\title{
EXPERIMENTAL ANALYSIS OF A SCREEN-COVERED GROOVE HEAT PIPE
}

\author{
L. Krambeck ${ }^{\mathrm{a}}$ | ABSTRACT \\ G. A. Bartmeyer ${ }^{a}$, \\ P. H. D. Santos ${ }^{b}$, \\ In this research, a heat pipe with screen-covered groove capillary structure \\ was experimentally analyzed. The heat pipe was manufactured from a \\ copper tube with the external diameter of $9.45 \mathrm{~mm}$, inner diameter of \\ $6.20 \mathrm{~mm}$, and a total length of $200 \mathrm{~mm}$. A Wire Electrical Discharge \\ Machining, or Wire-EDM, was used to manufacture axial microgrooves in \\ the heat pipe. A layer of phosphor bronze mesh \#100 completed the \\ capillary structure. Distilled water was the working fluid and the loading \\ filling ratio was $60 \%$ of the evaporator volume. The condenser was cooled \\ by air forced convection, the adiabatic section was insulated with fiberglass, \\ and the evaporator was heated by an electrical resistor and it was insulated \\ from the environment with aeronautic insulation. The heat pipe was tested \\ in horizontal position, under different heat loads varying from 5 up to $30 \mathrm{~W}$. \\ The experimental results showed that the screen-covered groove worked \\ satisfactorily as a capillary structure. \\ Received: April 14, 2018 \\ Revised: May 11, 2018 \\ Accepted: May 30, 2018 \\ Keywords: heat pipe, capillary structure, screen-covered groove, \\ experimental analysis
}

\section{NOMENCLATURE}

$\mathrm{N} \quad$ number of microgrooves

$\mathrm{q}$ heat transfer rate, $\mathrm{W}$

$\mathrm{R}_{\mathrm{th}}$ thermal resistance, ${ }^{\circ} \mathrm{C} / \mathrm{W}$

$\mathrm{t}$ time, $\mathrm{s}$

$\mathrm{T}$ temperature, ${ }^{\circ} \mathrm{C}$

W microgroove width, $\mathrm{m}$

$\mathrm{w}_{\mathrm{f}}$ microgroove thickness, $\mathrm{m}$

\section{Greek symbols}

$\delta \quad$ microgroove depth, $\mathrm{m}$

$\phi \quad$ wire diameter from the wire-EDM process, $\mathrm{m}$

\section{Subscripts}

adiab adiabatic section

cond condenser

evap evaporator

op operation

\section{INTRODUCTION}

The modern electronic technology lead to the electronic device miniaturization and the higher switching speeds, which created a significant demand for achieving high heat dissipation rates (Antonini Alves and Altemani, 2012). The existing electronic cooling techniques cannot be effective, affecting the performance, cost, and reliability of electronic devices (Ghajar and Darabi, 2014). Hence, according to Çengel and Ghajar(2015), the thermal management of electronic packaging has become a key technique in many applications. The heat pipes are passive devices based on phase change of the working fluid, which can be a good technological solution to the stabilization of microelectronic devices temperature (Krambeck et al., 2017). Major advantages of heat pipes include a very high thermal conductance, no moving parts, no pumping power requirements, and relatively low pressure drops (Faghri, 2014).

According to Groll and Rösler (1992), the heat pipes operate as the following principle: in the evaporator region, heat is transferred to the heat pipe, vaporizing the working fluid contained inside this region. The steam generated is moved, due to the pressure and density differences, to the cooling regions of the heat pipe (condenser region) where heat transported is rejected to the cold source. In the heat rejection process, the steam condenses, and the condensate returns back to the evaporator closing the cycle. The adiabatic region, which may have variable dimensions (in some cases it is absent) is located between the evaporator and the condenser being insulated from the external environment. The working fluid returns from the condenser to the evaporator due to capillary pumping effect. A schematic diagram of the operating principle of heat pipes is presented in Fig. 1.

A heat pipe consists essentially of three components: an involucre, a working fluid, and a capillary structure. The capillary structure of heat pipes can be made of screen meshes, grooves, or sintered metal powder. As an alternative to improve the thermal performance of the heat pipes, some 
composite capillary structures can be developed (Paiva and Mantelli, 2015). The screen-covered groove capillary structure is an example. In this kind of capillary structure, a mesh screen is used to improve the development of a large capillary pumping pressure. Already, the axial grooves ensure low resistance to the liquid flow and the highly conductive groove fins ensure low resistance to heat flow in the radial direction (Reay et al., 2014).

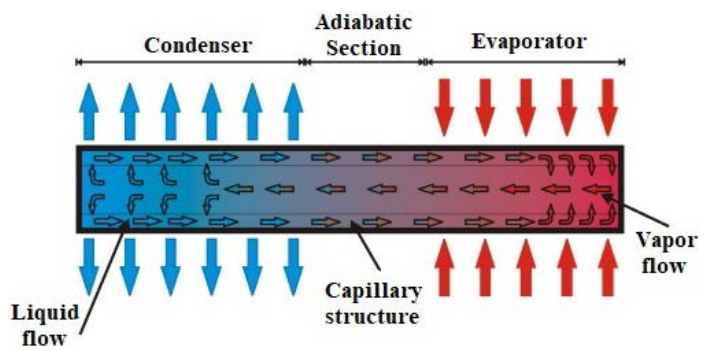

Figure 1. Sketch of a heat pipe.

More details on the principle of the heat pipes can be found in Chi (1976), Peterson (1994), Faghri (2014), and Reay et al. (2014)

In this context, this research presents a thermal performance experimental analysis of a heat pipe with screen-covered groove capillary structure operating horizontally. Due to the geometric characteristics, the heat pipe can be used in thermal management of electronic equipment.

\section{EXPERIMENTS ANALYSIS}

The methodology for manufacture (cleaning, assembly, tightness test, evacuation procedure, and filling with the working fluid); test; and analysis of the heat pipe were developed based on Nishida (2016), Russo et al. (2016), Krambeck et al. (2017), and Santos et al. (2017).

\section{Description of the Experimental Device}

A heat pipe was produced by copper tube with an outer diameter of $9.45 \mathrm{~mm}$, an inner diameter of $6.20 \mathrm{~mm}$, and a length of $200 \mathrm{~mm}$. The heat pipe has an evaporator region with $80 \mathrm{~mm}$ in length, an adiabatic section of $20 \mathrm{~mm}$ in length, and a condenser region with $100 \mathrm{~mm}$ in length. The working fluid used was distilled water with a filling ratio of $60 \%$ of the evaporator volume. Table 1 shows the main characteristics of the heat pipe analyzed in this research.

Table 1. Heat pipe main characteristics.

\begin{tabular}{|c|c|}
\hline Parameter & Value \\
\hline Inner diameter [mm] & 6.20 \\
\hline Outer diameter [mm] & 9.45 \\
\hline Evaporator length [mm] & 80 \\
\hline Adiabatic section length [mm] & 20 \\
\hline Condenser length [mm] & 100 \\
\hline
\end{tabular}

\begin{tabular}{|c|c|}
\hline Working fluid & Distilled water \\
\hline Volume of working fluid [mL] & 1.60 \\
\hline Filling ratio [\%] & 60 \\
\hline Capillary structure & $\begin{array}{c}\text { Screen-covered } \\
\text { microgroove }\end{array}$ \\
\hline
\end{tabular}

The internal capillary structure of the heat pipe is composed by a screen-covered microgroove. First of all, the axial microgrooves were fabricated in a straight copper tube by Wire Electrical Discharge Machining (Wire-EDM) - Nishida (2016). A scheme of microgroove profile is illustrated in Fig. 2a. Figure $2 b$ shows the image in micro-scale of the micro grooves with an average diameter of $220 \mu \mathrm{m}$. The image was obtained by Backscattered Electron Detector (BSD) for Scanning Electron Microscope (SEM).

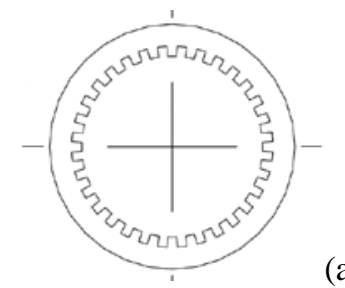

(a)

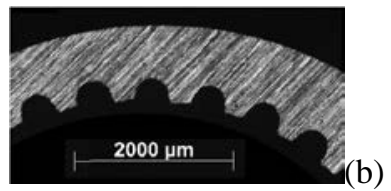

Figure 2. Capillary structure of microgrooves.

Figure 3 presents a schematic diagram of the microgroove geometric configuration and Table 2 shows the dimensions of the microgrooves. In the nomenclature used in this research, $w$ represents the microgroove width $[\mathrm{m}], \mathrm{w}_{\mathrm{f}}$ is the microgroove thickness [m], $\delta$ is the microgroove depth [m], and $\phi$ is the wire diameter from the Wire-EDM process [m], in this case, $\phi=25 \mu \mathrm{m}$.

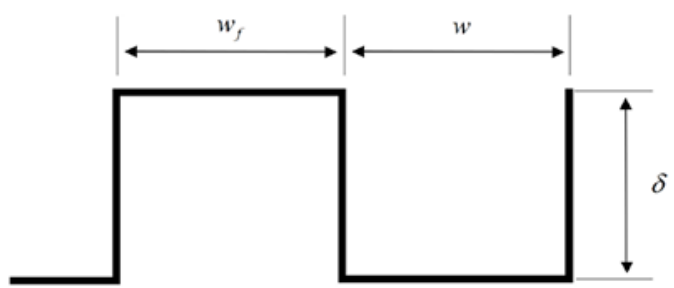

Figure 3. Schematic diagram of the microgroove geometric configuration.

Table 2. Characteristics of microgrooves.

\begin{tabular}{|c|c|c|}
\hline Parameter & Symbol & Value \\
\hline $\begin{array}{c}\text { Wire diameter from the } \\
\text { Wire-EDM process [m] }\end{array}$ & $\phi$ & $25 \mu$ \\
\hline Microgroove depth [m] & $\delta$ & $1.2 \phi(30 \mu)$ \\
\hline Microgroove width [m] & $\mathrm{w}$ & $1.4 \phi(35 \mu)$ \\
\hline Groove thickness [m] & $\mathrm{w}_{\mathrm{f}}$ & $1.4 \phi(35 \mu)$ \\
\hline Number of microgrooves & $\mathrm{N}$ & 32 \\
\hline
\end{tabular}


A screen mesh completed the capillary structure. The mesh configuration used was a single layer of phosphor bronze mesh \#100 - Fig. 4a. A micro-scale image of screen mesh is shown in Fig.4b.

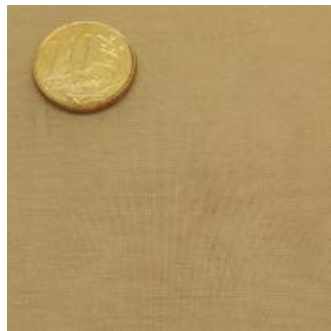

(a)

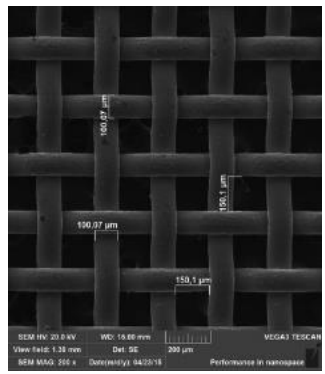

(b)

Figure 4. Image of phosphor bronze screen mesh \#100.
Figure 5 presents the final capillary structure manufactured, the screen-covered groove capillary structure.

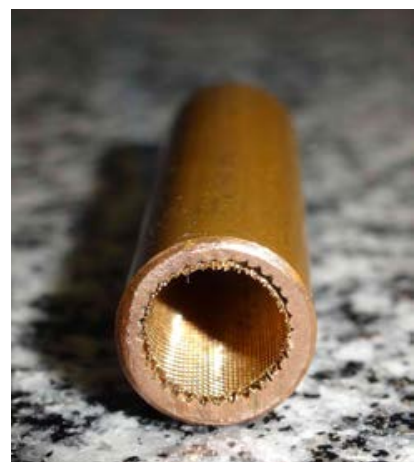

Figure 5. General view of the screen-covered groove capillary structure.

\section{Description of Experimental Apparatus}

The essential experimental apparatus used for the experimental tests, shown in Fig. 6, is composed of a power supply unit (Agilent ${ }^{T M}$ U8002A), a data logger (Agilent ${ }^{T M}$ 34970A) with 20 channels, a laptop $\left(\right.$ Dell $\left.^{T M}\right)$, a universal support, a uninterruptible power supply $\left(N H S^{T M}\right)$, and an fan $\left(\right.$ Ultrar $\left.^{T M}\right)$.

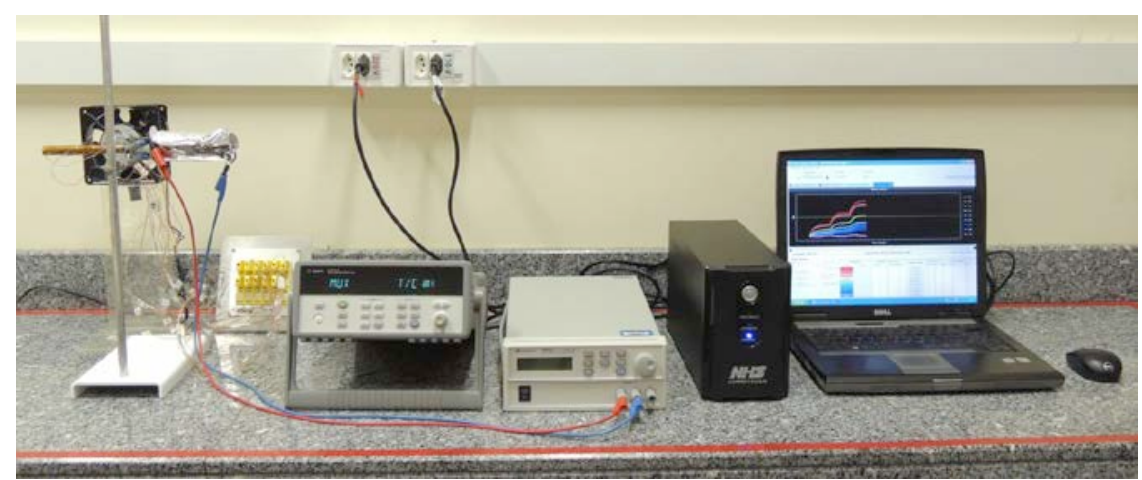

Figure 6. Experimental apparatus.

For the evaluation of the thermal performance of the heat pipe, K-type thermocouples (Omega Engineering $^{T M}$ ) were used. They were fixed on the outer surface of heat pipe by a thermosensitive adhesive strip $\left(\right.$ Kapton $\left.^{T M}\right)$. As shown in Figure 7, there were three thermocouples in the evaporator ( $T_{\text {evap, } 1}, T_{\text {evap,2, and }} T_{\text {evap,3 }}$ ), one thermocouple in the adiabatic section $\left(\mathrm{T}_{\text {adiab}}\right)$, and four thermocouples in the condenser $\left(T_{\text {cond, } 1}, T_{\text {cond, } 2}, T_{\text {cond,3, }}\right.$, and $\left.T_{\text {cond, } 4}\right)$ of the heat pipe.
The heating system of the evaporator was conducted by power dissipation in a power strip resistor (Omega Engineering ${ }^{T M}$ ). To ensure that the generated heat by Joule effect was transmitted to the evaporator, an aeronautic thermal insulation and a layer of polyethylene were installed in this region. A fiberglass tape was used in adiabatic section as heat insulation between the support and the heat pipe. The cooling system using air forced convection was consisted of a fan in the condenser region.

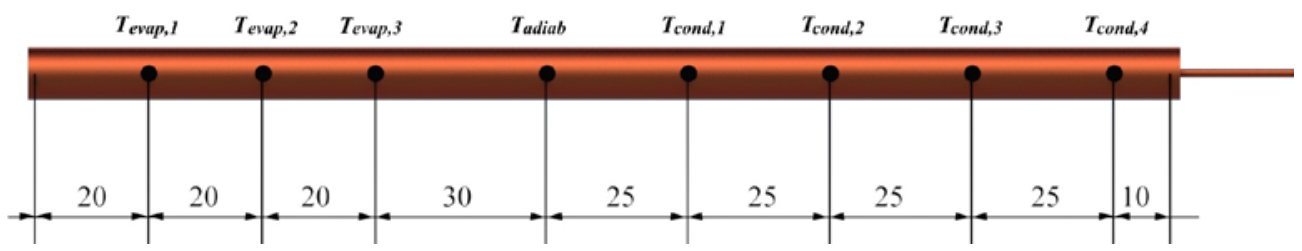

Figure 7. Thermocouple positions [mm]. 


\section{Experimental Procedure}

To ensure the best results and the repeatability of experimental tests, the ambient temperature was maintained at $20.0^{\circ} \mathrm{C} \pm 1.0^{\circ} \mathrm{C}$ by the thermal conditioning system $\left(\right.$ Carrier $\left.^{T M}\right)$. The heat pipe was carefully fixed to the universal support with bracket in the adiabatic region at the horizontal position. The fan was turned on, positioned correctly in the condenser region and set at a speed of $5.0 \mathrm{~m} / \mathrm{s}$ with a combined error of $\pm 0.2 \mathrm{~m} / \mathrm{s}$. The data acquisition system was turned on, and the temperatures measured by the K-type thermocouples. The power supply unit was turned on and adjusted to the dissipation power desired. The initial load was 5W and, after approximately 15 minutes, the thermocouples showed stationary values. The load increment was made until the maximum average temperature of the passive device reached the critical temperature $\left(160^{\circ} \mathrm{C}\right)$, where the melting of the materials could happen. Data was acquired every 5s, recorded in the laptop by the software Agilent ${ }^{T M}$ Benchlink Data Logger 3.

The experimental uncertainties are associated to the K-type thermocouples, the data logger, and the power supply unit. The experimental temperature uncertainty is estimated to be approximately $\pm 1.27^{\circ} \mathrm{C}$ and a thermal load was $\pm 1 \%$. For the uncertainties determination, the error propagation method described by Holman (2011) was used.

\section{Data Reduction}

The total thermal resistance, $\mathrm{R}_{\mathrm{th}}$, of a heat pipe can be defined as the difficulty of the device to carry heat. The higher the thermal resistance, the greater the difficulty is in transporting heat from the system (Bergman et al., 2017). The total thermal resistance can be calculated by

$$
\mathrm{R}_{\mathrm{th}}=\frac{\Delta \mathrm{T}}{\mathrm{q}}=\frac{\left(\mathrm{T}_{\text {evap }}-\mathrm{T}_{\text {cond }}\right)}{\mathrm{q}}
$$

where, $\mathrm{q}$ is the heat transfer capability of the device [W], $\mathrm{T}_{\text {evap }}$ and $\mathrm{T}_{\text {cond }}$ are the average wall temperature of the evaporator and the condenser, respectively $\left[{ }^{\circ} \mathrm{C}\right]$.

\section{RESULTS AND DISCUSSION}

The experimental results regarding thermal performance of the heat pipe using distilled water as the working fluid are presented considering the horizontal position. The experimental tests were repeated three times and the errors were compared taking into account the difference between the mean values were less than $0.5^{\circ} \mathrm{C}$. Tests were performed to a heat load varying from 5 to $30 \mathrm{~W}$. Figure 8 shows the temperature distribution as function of time for the heat pipe with screen-covered groove structure.

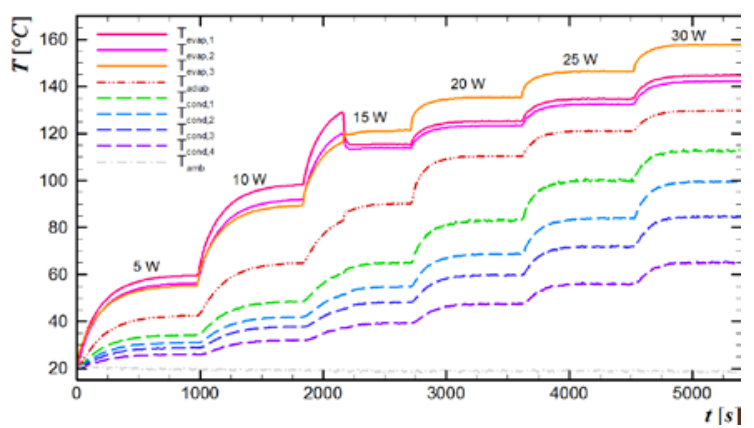

Figure 8. Temperature of the heat pipe versus time for different heat loads.

To ensure that the capillary structure worked successfully, the experimental results presents a thermal performance comparison between a rod, a thermosyphon, and the heat pipe manufactured, with the same geometry and characteristics. The operation temperature in function of the heat load for the three passive devices is shown in Fig. 9.

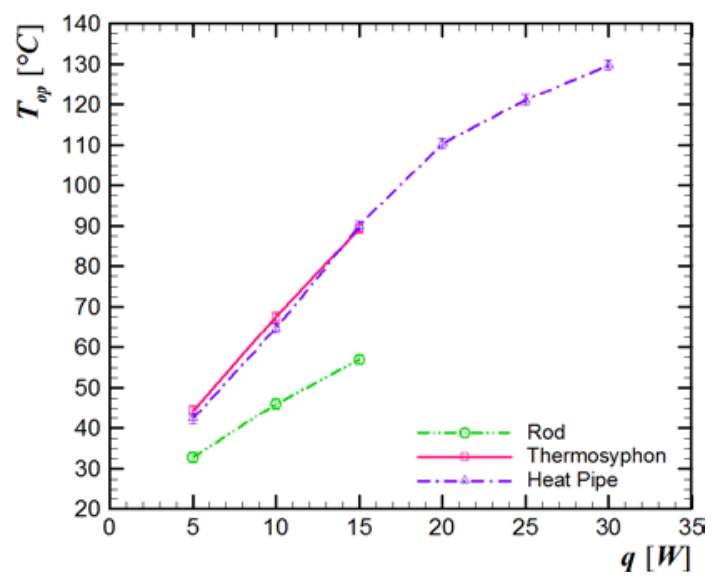

Figure 9. Operation temperature versus heat load.

Figure 10 presents the comparison of the thermal resistance versus the heat load. The heat pipe worked satisfactory, since the capillary structure provided to the heat pipe the operation in a higher load and lower thermal resistance.

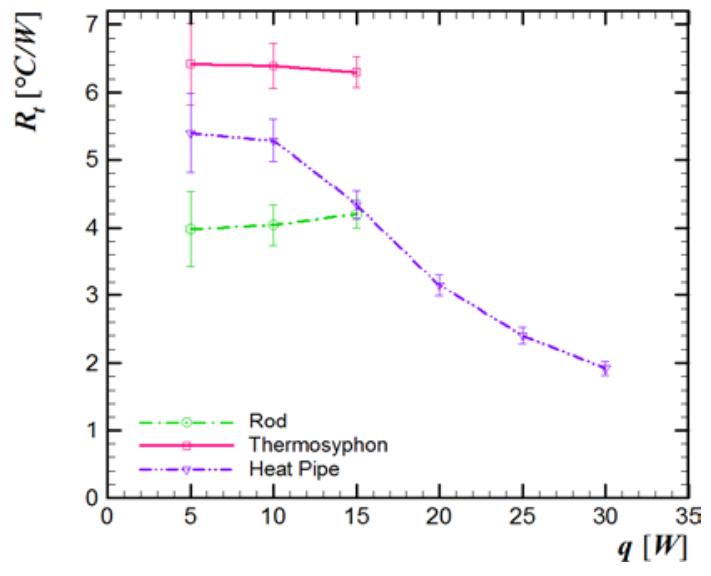

Figure 10. Thermal resistance versus heat load. 


\section{RESULTS AND DISCUSSION}

In this research, a screen-covered groove heat pipe was experimentally analyzed. Due to the shape and size, the heat pipe can be used in thermal management of electronic equipment. The heat pipe was $200 \mathrm{~mm}$ long, its inner and outer diameter was $6.20 \mathrm{~mm}$ and $9.45 \mathrm{~mm}$, respectively, and the working fluid was distilled water. Tests were performed to a heat load from 5 up to $30 \mathrm{~W}$ in horizontal position. The experimental results showed that the screencovered groove worked satisfactorily as a capillary structure.

\section{ACKNOWLEDGEMENTS}

Acknowledgments are provided to the Capes (Coordenação de Aperfeiçoamento de Pessoal de Nível Superior), the CNPq (Conselho Nacional de Desenvolvimento Científico e Tecnológico), the PROPPG/UTFPR (Pró-Reitoria de Pesquisa e PósGraduação), the DIRPPG/UTFPR (Diretoria de Pesquisa e Pós-Graduação), the PPGEM/UTFPR/ Câmpus Ponta Grossa (Programa de Pós-Graduação em Engenharia Mecânica), and the DAMEC/UTFPR/ Câmpus Ponta Grossa (Departamento Acadêmico de Mecânica).

\section{REFERENCES}

Antonini Alves, T., and Altemani, C. A. C., 2012, An Invariant Descriptor for Heaters Temperature Prediction in Conjugate Cooling, International Journal of Thermal Scinces, Vol. 58, pp. 092-101.

Bergman, T. L., Lavine, A. S., Incropera, F. P., and DeWitt, D. P., 2017, Fundamentals of Heat and Mass Transfer, John Wiley \& Sons.

Çengel, Y. A., and Ghajar, A. J., 2015, Heat and Mass Transfer: Fundamentals and Applications, McGraw-Hill.

Chi, S. W., 1976, Heat Pipe Theory and Practice: A Sourcebook, Hemisphere Publishing Corporation.

Ghajar, M., and Darabi, J., 2014, Evaporative Heat Transfer Analysis of a Micro Loop Heat Pipe with Rectangular Grooves, International Journal of Thermal Sciences, Vol. 79, pp. 51-59.

Groll, M., and Rösler, S., 1992, Operation Principles and Performance of Heat Pipes and Closed Two-Phase Thermosyphons, Journal of NonEquilibrium Thermodynamics, Vol. 17, pp. 091-151.

Faghri, A., 2014, Heat Pipes: Review, Opportunities and Challenges, Frontiers in Heat Pipes, Vol. 5, pp. 01-48.

Holman, J. P., 2011, Experimental Methods for Engineers, McGraw-Hill.

Krambeck, L., Nishida, F. B., Aguiar, V. M., Santos, P. H. D., and Antonini Alves, T., 2017,
Thermal Performance Evaluation of Different Passive Devices for Electronics Cooling, Thermal Science, OnLine-First Issue 00.

Nishida, F. B., 2016, Development of Heat Pipes with Microgrooves Fabricated by Wire Electrical Discharge Machining, Master Thesis, Universidade Tecnológica Federal do Paraná, Ponta Grossa, PR, Brasil.

Paiva, K. V., and Mantelli, M. B. H., 2015, Wire-Plate and Sintered Hybrid Heat Pipes: Model and Experimental, International Journal of Thermal Sciences, Vol. 93, pp. 36-51.

Peterson, G. P., 1994, An Introduction to Heat Pipes: Modeling, Testing and Applications, (Thermal Management of Microelectronic and Electronic System Series), Wiley-Interscience.

Reay, D. A., Kew, P. A., and McGlen, R. J., 2014, Heat Pipe: Theory, Design and Applications, Butterworth-Heinemann.

Russo, G. M., Krambeck, L., Nishida, F. B., Santos, P. H. D., and Antonini Alves, T., 2016, Thermal Performance of Thermosyphon for Different Working Fluids, Engenharia Térmica (Thermal Engineering), Vol. 15, No. 1, pp. 03-08.

Santos, P. H. D., Reis, L. S., Marquardt, L. S., Vicente, K. A. T., and Antonini Alves, T., 2017, Modeling and Experimental Tests of a Copper Thermosyphon, Acta Scientiarum, Technology, Vol. 39, pp. 59-68. 